\title{
Neurosupportive Role of Vanillin, a Natural Phenolic Compound, on Rotenone Induced Neurotoxicity in SH-SY5Y Neuroblastoma Cells
}

\author{
Chinnasamy Dhanalakshmi, ${ }^{1}$ Thamilarasan Manivasagam, ${ }^{1}$ Jagatheesan Nataraj, ${ }^{1}$ \\ Arokiasamy Justin Thenmozhi, ${ }^{1}$ and Musthafa Mohamed Essa ${ }^{2,3,4}$ \\ ${ }^{1}$ Department of Biochemistry and Biotechnology, Annamalai University, Annamalainagar, Tamil Nadu 608002, India \\ ${ }^{2}$ Department of Food Science and Nutrition, CAMS, Sultan Qaboos University, Muscat, Oman \\ ${ }^{3}$ Ageing and Dementia Research Group, Sultan Qaboos University, Muscat, Oman \\ ${ }^{4}$ Food and Brain Research Foundation, Chennai, Tamil Nadu 600094, India \\ Correspondence should be addressed to Thamilarasan Manivasagam; mani_pdresearchlab@rediffmail.com \\ and Musthafa Mohamed Essa; drmdessa@gmail.com
}

Received 10 September 2015; Accepted 12 October 2015

Academic Editor: Jose M. Prieto

Copyright (c) 2015 Chinnasamy Dhanalakshmi et al. This is an open access article distributed under the Creative Commons Attribution License, which permits unrestricted use, distribution, and reproduction in any medium, provided the original work is properly cited.

\begin{abstract}
Vanillin, a phenolic compound, has been reported to offer neuroprotection against experimental Huntington's disease and global ischemia by virtue of its antioxidant, anti-inflammatory, and antiapoptotic properties. The present study aims to elucidate the underlying neuroprotective mechanism of vanillin in rotenone induced neurotoxicity. Cell viability was assessed by exposing SHSY5Y cells to various concentrations of rotenone $(5-200 \mathrm{nM})$ for $24 \mathrm{~h}$. The therapeutic effectiveness of vanillin against rotenone was measured by pretreatment of vanillin at various concentrations $(5-200 \mathrm{nM})$ and then incubation with rotenone (100 $\mathrm{nM})$. Using effective dose of vanillin $(100 \mathrm{nM})$, mitochondrial membrane potential, levels of reactive oxygen species (ROS), and expression patterns of apoptotic markers were assessed. Toxicity of rotenone was accompanied by the loss of mitochondrial membrane potential, increased ROS generation, release of cyt-c, and enhanced expressions of proapoptotic and downregulation of antiapoptotic indices via the upregulation of p38 and JNK-MAPK pathway proteins. Our results indicated that the pretreatment of vanillin attenuated rotenone induced mitochondrial dysfunction, oxidative stress, and apoptosis. Thus, vanillin may serve as a potent therapeutic agent in the future by virtue of its multiple pharmacological properties in the treatment of neurodegenerative diseases including PD.
\end{abstract}

\section{Introduction}

Parkinson's disease (PD) is one of the most common, progressive, and age-related neurodegenerative diseases, that is, raised by the selective loss of dopaminergic (DA) neurons in substantia nigra pars compacta and resulting in striatal dopamine depletion leading to movement disorder [1]. Though the cause of PD is not known, most of the knowledge about PD pathology is gathered from various in vivo and in vitro models. Rotenone, a naturally occurring plant flavonoid and widely used pesticide, is a specific inhibitor of complex I of the mitochondrial respiratory chain and mimicked the symptoms of $\mathrm{PD}$, both in vivo and in vitro conditions [2-5].
The SH-SY5Y cell line is considered as the excellent cellular model for PD research because this cell line possesses many characteristics (expression of tyrosine hydroxylase, dopamine-beta-hydroxylase, and dopamine transporter) of DAergic neurons [6]. Epidemiological studies suggest that exposure to environmental agents, such as pesticides, may increase the PD risk [7, 8]. Mitochondrial dysfunction has also been linked to PD. In vitro rotenone model of PD authenticated the involvement of both mitochondrial dysfunction and environmental exposures in PD.

The in vitro studies indicated that rotenone can easily cross the biological membranes, due to its lipophilic nature, 


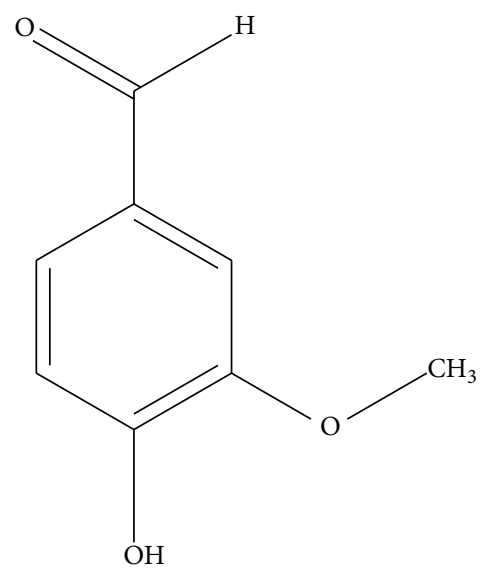

FIGURE 1: Structure of vanillin.

and could access the cytoplasm of dopaminergic neurons easily [3]. Furthermore it could enter into mitochondria and inhibit mitochondrial complex I activity. It can also induce ROS generation and loss of mitochondrial membrane potential (MMP) and release cytochrome c (cyt-c) from mitochondria, which in turn activate the caspase cascades via regulation of JNK, p38, and ERK MAPK pathways [2, 9].

Since current therapies are ineffective in preventing degeneration of dopaminergic neurons, it is imperative to identify novel drugs that delay the progression of PD. Phytoconstituents, those of a dietary origin especially present in fruits, vegetables, and spices, have been a subject of intense investigation in recent years for their therapeutic potential in a multitude of age-related chronic ailments such as cardiovascular, endocrine, neoplastic, and neurodegenerative diseases [10-13]. Vanillin (4-hydroxy-3-methoxybenzaldehyde), whose chemical structure is shown in Figure 1, is the principal component of the bean and pod of tropical vanilla orchids (Vanilla planifolia, Vanilla tahitensis, and Vanilla pompona). It is one of the most widely used flavor components in beverage, food preservatives, cosmetics, and drugs industry, with an estimated annual worldwide consumption of more than 2000 tons [14]. Besides its industrial and food application, vanillin exhibits antimicrobial activity [15] as well as antimutagenic [16] and anticarcinogenic actions [17].

Moreover, vanillin can inhibit peroxynitrite-mediated reactions that are known to be involved in the pathogenesis of several neurodegenerative diseases such as Alzheimer's and Parkinson's diseases [18]. Vanillin has been shown to control cognitive decline, mitochondrial dysfunction, oxidative stress, and neurodegeneration in experimental model of Huntington's disease [19]. Vanillin reduces the expressions of proinflammatory cytokines (interleukin- $1 \beta$ and interleukin6 , interferon- $\beta$, and tumor necrosis factor- $\alpha$ ) and stimulates the expression of anti-inflammatory cytokine (IL-4) in tissues [20]. It has been reported to show significant brain protective property by reducing the levels of reactive oxygen/ nitrogen species and augmenting the activities of antioxidant enzymes [21]. The biological properties of vanillin are mainly attributed to the presence of phenolic group, ether and aldehyde moieties. Till now the effect of vanillin on rotenone induced PD like neurotoxicity is not well explored. Moreover in vitro rotenone model of PD has been used for identifying potential neuroprotective agents [22] including various herbs [23] and novel antiparkinsonian drugs [24] for treating PD. Based on this, the present study was designed to find out the protective effects of vanillin on the mitochondrial dysfunction, oxidative stress, and apoptotic damage produced in rotenone exposed SH-SY5Y neuroblastoma cells.

\section{Materials and Methods}

2.1. Chemicals. Rotenone, vanillin, 3-(4,5-dimethylthiazol-2yl)-2,5-diphenyltetrazolium bromide (MTT), 2-7-diacetyl dichlorofluorescein (DCFH-DA), rhodamine 123 (Rh-123), heat-inactivated fetal bovine serum (FBS), Dulbecco's modified Eagle's medium (DMEM), antibiotic/antimycotic, EDTA, and Trypsin-EDTA were procured from Sigma Chemicals Co. (St. Louis, USA). Anti-Bcl-2, anti-Bax, caspase-3, caspase-8, caspase-9, cyt-c, and anti-JNK and anti-P38 MAPK antibodies were obtained from Cell Signaling (USA) and $\beta$ actin, anti-mouse, and anti-rabbit secondary antibodies were purchased from Santa Cruz Biotechnology, Inc. (USA).

2.2. Cell Culture. SH-SY5Y cells were obtained from National Center for Cell Science (NCCS), Pune, India. The cells were grown in DMEM supplemented with 10\% FBS and 1\% antibiotic/antimycotic solution. Cultures were maintained in a humidified incubator at $37^{\circ} \mathrm{C}$ in an atmosphere of $5 \% \mathrm{CO}_{2}$ and $95 \%$ air. Cell culture medium was changed every 2 days.

2.3. Cell Viability Assay. Cell viability assay was determined by MTT assay, as described previously [25]. SH-SY5Y cells were collected and seeded in 96 -well plates, at a density of $3 \times$ $10^{3}$ cells/well. To determine the toxicity of rotenone, cells were incubated with different concentrations of rotenone $(5,10,50$, 100 , and $200 \mathrm{nM})$ and vanillin $(5 \mathrm{nM}, 10 \mathrm{nM}, 20 \mathrm{nM}, 50 \mathrm{nM}$, $100 \mathrm{nM}, 200 \mathrm{nM}, 500 \mathrm{nM}, 1 \mu \mathrm{M}, 10 \mu \mathrm{M}, 100 \mu \mathrm{M}, 200 \mu \mathrm{M}$, and $500 \mu \mathrm{M})$ for $24 \mathrm{~h}$ and MTT assay was performed to detect $\mathrm{IC}_{50}$ value of rotenone and vanillin. To assess the therapeutic efficacy of vanillin against rotenone toxicity, cells were pretreated with different concentrations of vanillin (5, $10,20,50,100$, and $200 \mathrm{nM}$ ) for $2 \mathrm{~h}$ and then incubated with rotenone (effective dose) for $24 \mathrm{~h}$. Vanillin was also present during rotenone treatment for additional $24 \mathrm{~h}$. Then all the cells were incubated with MTT final concentration $(1 \mathrm{mg} / \mathrm{mL}$ of serum-free DMEM medium) at $37^{\circ} \mathrm{C}$ for $4 \mathrm{~h}$. After the incubation, the medium was removed, and $100 \mu \mathrm{L}$ of DMSO was added to dissolve the formazan crystals. The absorbance of formazan product was evaluated by spectrophotometer at $570 \mathrm{~nm}$ using a microplate reader. Four independent experiments were performed from each group.

Based on the results obtained from cell viability assay, the effective dose of vanillin against rotenone toxicity was utilized to study the effect of vanillin by assessing ROS, MMP, apoptosis, and apoptotic markers protein expression.

\subsection{Experimental Design ( $n=4$ Experiments)}

Group I: untreated control cells. 
Group II: rotenone (effective dose: $100 \mathrm{nM}$ ).

Group III: vanillin $(100 \mathrm{nM})+$ rotenone $(100 \mathrm{nM})$.

Group IV: vanillin (100 nM).

2.5. Measurement of Intracellular ROS. The levels of endogenous ROS formed in control and experimental cells were estimated by using fluorescence dye (DCFH-DA) [26]. After pretreatment with vanillin $(100 \mathrm{nM} / \mathrm{mL})$ for $2 \mathrm{~h}$, the cells $(1 \times$ $10^{5}$ cells/well in 6-well plates) were incubated with rotenone $(100 \mathrm{nM} / \mathrm{mL})$ for $24 \mathrm{~h}$ and then incubated with $100 \mu \mathrm{L} \mathrm{DCFH-}$ $\mathrm{DA}$ for $30 \mathrm{~min}$ at $37^{\circ} \mathrm{C}$ and washed twice with $\mathrm{PBS}$ to remove the excess probe; the cells were suspended in glucoseenriched PBS and transferred to a fluoroslide and visualized using a fluorescent microscope. Fluorescent measurements were made with excitation and emission filters set at $485 \pm$ $10 \mathrm{~nm}$ and $530 \pm 12.5 \mathrm{~nm}$, respectively (Shimadzu RF-5301 PC spectrofluorimeter), and the images were captured using fluorescence microscope [27].

2.6. Measurement of Mitochondrial Transmembrane Potential (MMP). MMP changes were determined by the mitochondrial-specific, incorporation of a cationic fluorescent dye Rh-123 [28]. After treatment with vanillin for $2 \mathrm{~h}$ and rotenone for $24 \mathrm{~h}$ as previously described, the cells $(1 \times$ $10^{5}$ cells/well in 6-well plates) were changed to fresh medium containing $1 \mu \mathrm{L}$ of fluorescent dye Rh-123 (5 mmol/L) and kept for $30 \mathrm{~min}$ at $37^{\circ} \mathrm{C}$. The cells were then collected, washed twice with PBS, and estimated by using blue filter (450$490 \mathrm{~nm}$ ) (Shimadzu RF-5301 PC spectrofluorimeter).

2.7. Apoptosis Analysis Using Dual Staining. Dual staining method is used to analyze the apoptotic morphological changes by treating the control and experimental cells with fluorescent probes acridine orange and ethidium bromide ( $\mathrm{AO}$ and EB) and using fluorescence microscope [29]. After treatment schedule as described in previous experiments, medium was removed from the plates; cells $\left(1 \times 10^{5}\right)$ were washed with PBS twice and then fixed with $4 \%$ paraformaldehyde for $20 \mathrm{~min}$ and stained with $100 \mu \mathrm{g} / \mathrm{mL} \mathrm{AO}$ and EB. These cells were incubated for $20 \mathrm{~min}$ at room temperature and washed with warm PBS to remove excess dye. Cellular morphology was examined using fluorescence microscopy and photographed and quantified at $535 \mathrm{~nm}$ in spectrofluorometer.

2.8. Immunoblotting and Image Analysis. SH-SY5Y cells $(1 \times$ $10^{5}$ ) in 6-well plates, after $2 \mathrm{~h}$ pretreatment with vanillin and $24 \mathrm{~h}$ treatment with rotenone, were harvested, washed with PBS, and lysed in $100 \mu \mathrm{L}$ lysis buffer (20 mM Tris-HCl, pH 7.4, $150 \mathrm{mM} \mathrm{NaCl}, 1 \mathrm{mM}$ EDTA, $30 \mu \mathrm{g} / \mathrm{mL}$ apoprotein, and $1 \mathrm{mM}$ phenylmethylsulfonyl fluoride) followed by centrifugation at $1,000 \mathrm{~g}$ for $5 \mathrm{~min}$ at $4^{\circ} \mathrm{C}$. The supernatants (cytosolic fractions) were saved and the pellets solubilized in the same volume of mitochondrial lysis buffer $(50 \mathrm{mM}$ Tris $\mathrm{pH} 7.4$, $150 \mathrm{mM} \mathrm{NaCl}, 2$ mM EDTA, 2 mM EGTA, 0.2\% Triton X-100, $0.3 \% \mathrm{NP}-40,100 \mu \mathrm{M}$ PMSF, $10 \mu \mathrm{g} / \mathrm{mL}$ leupeptin, and $2 \mu \mathrm{g} / \mathrm{mL}$ apoprotein) kept on ice and vertex for $20 \mathrm{~min}$ followed by pelleting at $10000 \mathrm{~g}$ for $10 \mathrm{~min}$ at $4^{\circ} \mathrm{C}$ and subjected to $12.5 \%$ polyacrylamide gel electrophoresis lane [13]. The separated proteins were blotted onto a PVDF membrane by semidry transfer (BIORAD). After blocking with 5\% nonfat milk in TBS at $25^{\circ} \mathrm{C}$ for $1 \mathrm{~h}$, blots were probed with various antibodies: caspase-3, caspase-8, and caspase-9, cytochrome c, Bax, $\mathrm{Bcl}_{2}, \mathrm{p}$-JNK, and p-P38 and p-ERK $(1: 1,000)$ and $\beta$-actin $(1: 2,000)$. Horseradish peroxidase-conjugated anti-mouse or anti-rabbit IgG were used as the secondary antibodies at a concentration of $1: 2,000$. Then the membranes were washed with Tris-buffered saline and $0.05 \%$ Tween-20 thrice for 10 min interval, after extensive washes in TBST. Bands were scanned using a scanner and quantified by Image J, a public domain Java Image processing software, Wayne Rasband, $\mathrm{NIH}$, Bethesda, MD, USA, in which the control group was set to100\% [30].

2.9. Data Analysis. Statistical analysis was performed by oneway analysis of variance followed by Duncan's multiple range test (DMRT) using Statistical Package for the Social Science (SPSS) software package version 12.0. Results were expressed as mean $\pm \mathrm{SD}$ for four experiments in each group. $p<0.05$ were considered significant.

\section{Results}

3.1. Cytotoxicity of Rotenone in SH-SY5Y Cells. A dosedependent cytotoxic effect of rotenone was evaluated by MTT assay in SH-SY5Y human neuroblastoma cells, which measures mitochondrial function or integrity with a dose of $100 \mathrm{nM}$ which caused $~ 50 \%$ of cell death as compared with controls and was taken as inhibitory dose (Figures 2(a) and 2(b)).

3.2. Vanillin Protects Rotenone Induced SH-SY5Y Cell Death. Figure 3 shows the protective effect of vanillin against rotenone induced injury $(100 \mathrm{nM})$ with cell viability increasing to $84 \pm 6.7 \%$ of control in the presence of $100 \mathrm{nM}$ vanillin. So based on the dose-response data, the treatments of $100 \mathrm{nM}$ vanillin and $100 \mathrm{nM}$ rotenone were chosen for further experiments (Figure 3).

3.3. Vanillin Attenuates Rotenone Induced ROS Generation. To analyze the effect of vanillin on free radical generation, the levels of intracellular ROS formed were quantified by fluorescence with $\mathrm{H}_{2}$ DCF-DA. Rotenone treatment enhanced the green fluorescence, an indicator of high levels of ROS, and pretreatment of vanillin to rotenone exposed cells revealed reduced green color intensity, an indicator of decreased intracellular ROS formation (Figures 4(a) and 4(b)).

3.4. Vanillin Ameliorates Rotenone Induced Mitochondria Membrane Potential. Alteration in the MMP is considered to be one of the important events related to apoptosis. The effect of vanillin on MMP in rotenone induced toxicity was analyzed by measuring the uptake of Rh-123. In normal cells, Rh-123 steadily penetrates the cells, stains mitochondria, and exhibits high fluorescent intensity. The depolarization of 


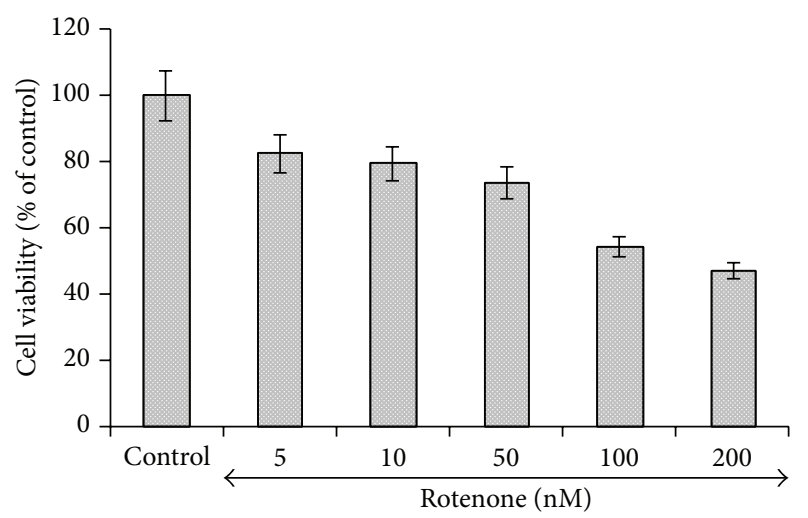

(a)

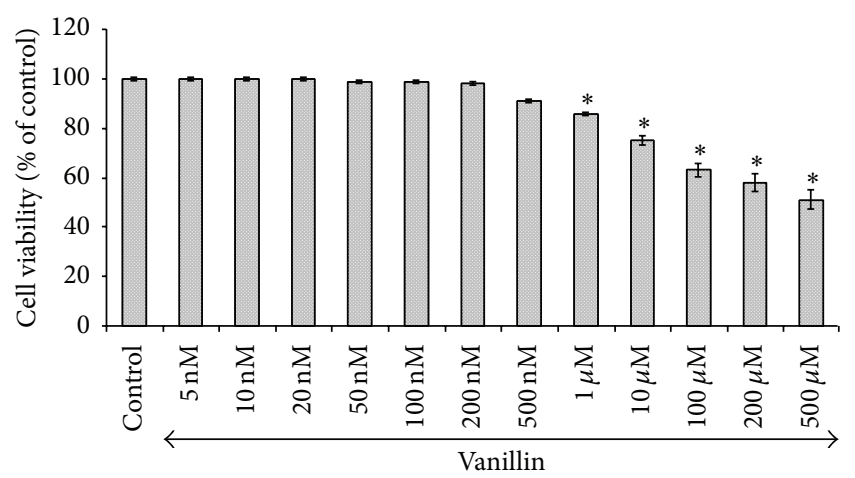

(b)

FIGURE 2: Effect of vanillin on rotenone induced cytotoxicity (MTT assay) in SH-SY5Y neuroblastoma cells. Cell viability was determined by measuring MTT method. (a) shows the dose-dependent effect of rotenone $(5,10,50,100$, and $200 \mathrm{nM})$ induced cell toxicity after $24 \mathrm{~h}$. An approximately half-maximal inhibition of cell viability was obtained at $100 \mathrm{nM}$ rotenone concentration. (b) shows the dose-dependent effect of vanillin at various concentrations. Low concentrations $(5,10,20,50,100$, and $200 \mathrm{nM})$ did not induce any toxicity after $24 \mathrm{~h}$ treatment, whereas slight toxicity was induced at $500 \mu \mathrm{M}$ concentration. Values are expressed as the percentage of the untreated control and represented as mean \pm SD of four independent experiments in each group.

MMP due to rotenone treatment results in the loss of Rh-123 from the mitochondria and a decrease in intracellular green fluorescence. Cell cultures pretreated with vanillin before rotenone treatment partially reduced this decline in fluorescence and approached control levels (Figure 5).

3.5. Vanillin Shields Rotenone Induced Apoptotic Changes (Cellular Morphology). Double staining of rotenone and vanillin treated SH-SY5Y cells, with AO and EB, was used to determine the rate of apoptosis. Control cells which fluoresced brightly with green nuclei and normal morphology were showed in Figure 6(a). In contrast, at $100 \mathrm{nM}$ rotenone exposure, cells revealed orange luminescent apoptotic body formation, when compared to control $(p<0.05)$, and treatment with vanillin increased cell viability and decreased apoptotic cell death when compared to cells exposed merely to rotenone (Figure 6(b)).

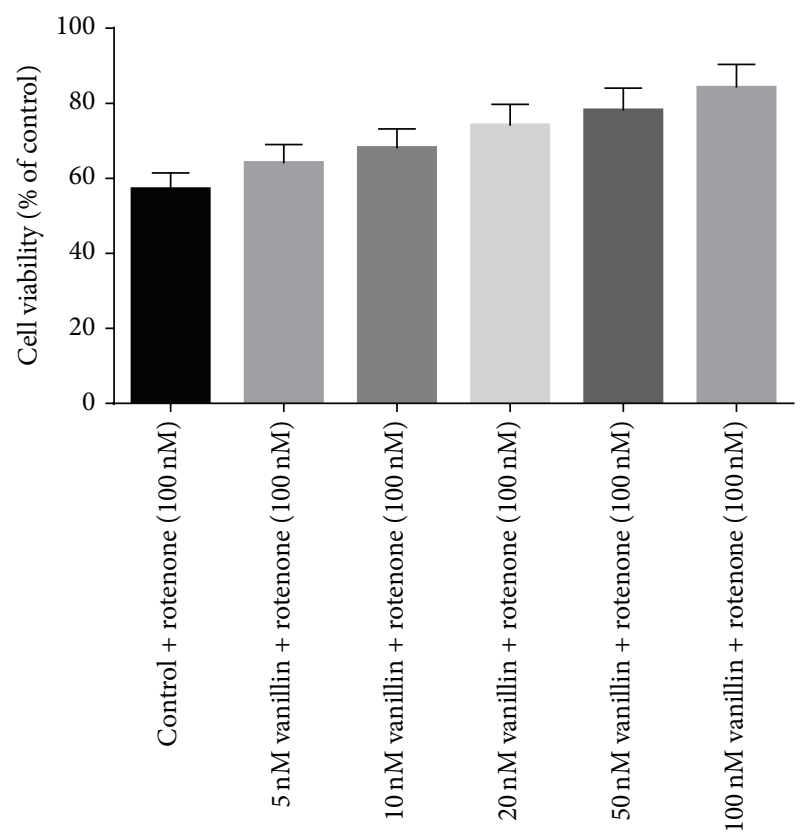

FIGURE 3: The protective effect of vanillin $(5,10,20,50$, and $100 \mathrm{nM})$ against rotenone induced cell death was determined by MTT assay. Values are expressed as the percentage of the untreated control and represented as mean \pm SD of four independent experiments in each group.

3.6. Vanillin Prevents Rotenone Induced Changes in Protein Expressions of Apoptotic and Signaling Markers. To further characterize the mechanism of inhibition by vanillin on rotenone induced apoptosis, we determined the effect of vanillin on the expression of anti- and proapoptotic proteins by western blot. The expression of Bax, caspase-3, caspase- 8 , and caspase- 9 was increased while the distribution of $\mathrm{Bcl}-2$ and cyt-c in mitochondria was significantly decreased by the rotenone treated group as compared with control. Rotenone treatment significantly diminished the translocation of cytc in cytosol. Pretreatment with vanillin gradually restored the imbalanced expression profile of these proteins. Vanillin, which had no effects in control cells, in contrast, when treated with rotenone noticeably, changes the protein expressions in SH-SY5Y cells (Figures 7(a), 7(b), and 7(c)). In order to elucidate the mechanism of rotenone induced cell death and protective effective of vanillin, the protein expression studies of signaling molecules were performed. Expressions of $\mathrm{p}$-JNK, p-P38, and p-ERK were significantly increased after rotenone treatment as compared with control. Following pretreatment with vanillin before rotenone addition is able to decrease the levels of p-JNK, p-P38, and p-ERK significantly. However, treatment with vanillin alone did not alter the expression; p-JNK, p-P38, and p-ERK were unaffected as compared to control (Figure 7(d)).

\section{Discussion}

Results of the present study indicated that the rotenone treatment for $24 \mathrm{~h}$ destroyed SH-SY5Y cells in a dose-dependent 


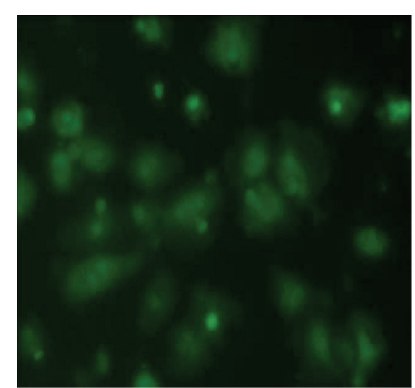

(A)

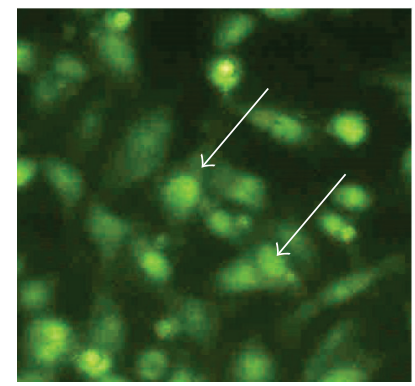

(C)

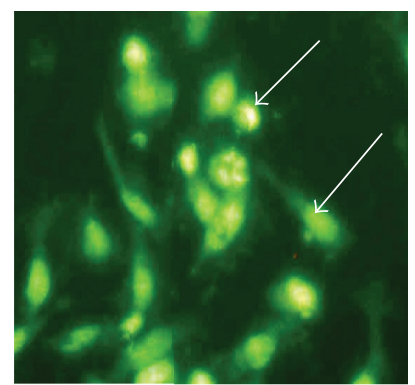

(B)

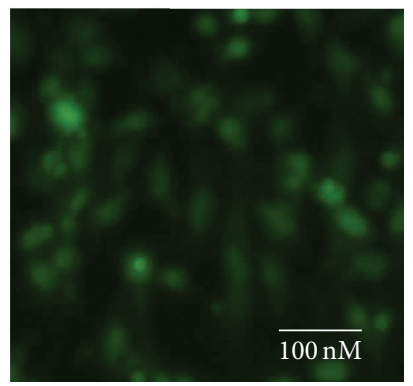

(D)

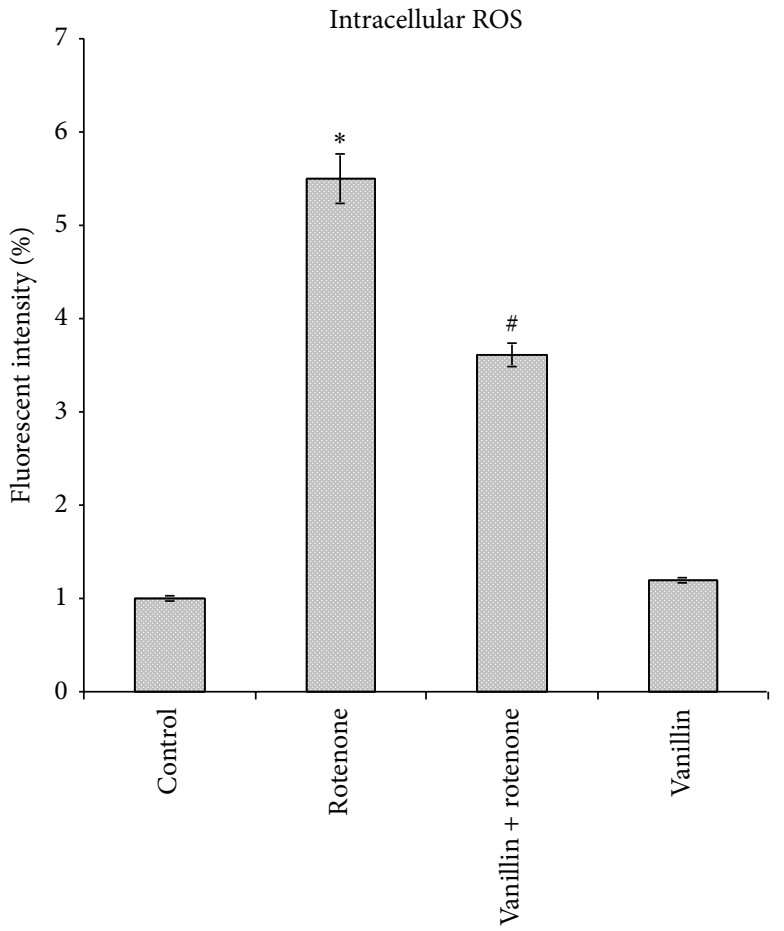

(b)

(a)

FIGURE 4: (a) Vanillin reduced ROS formation as stained by $1 \mu \mathrm{M}$ CM-H2 DCFDA. (a) Photomicrograph showing the preventive effect of vanillin $(100 \mathrm{nM}$ ) against rotenone induced ROS generation. (A) Control, (B) rotenone, (C) vanillin + rotenone, and (D) vanillin. (b) Rotenone $(100 \mathrm{nM})$ treatment significantly increased the levels of ROS as compared to control cells, while vanillin (100 nM) pretreatment significantly decreased the levels of ROS as compared to rotenone alone treated cells. Values are given as mean \pm SD of four independent experiments in each group. ${ }^{*} p<0.05$ compared to control and ${ }^{\#} p<0.05$ compared to rotenone group (DMRT).

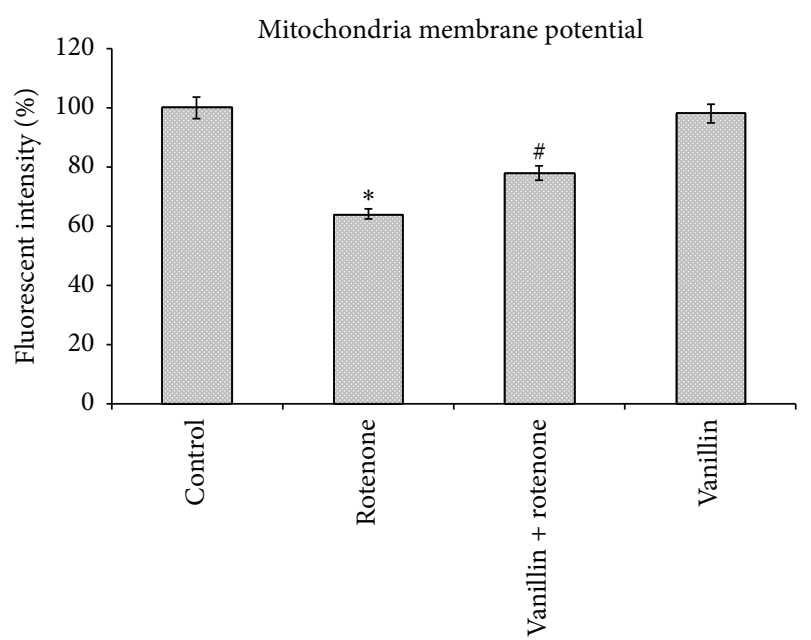

FIgURE 5: Vanillin stabilizes MMP as stained by Rh-123. Rotenone $(100 \mathrm{nM})$ significantly decreased mitochondria membrane potential, while cells that were pretreated with vanillin $(100 \mathrm{nM})$ significantly increased MMP. Values are given as mean \pm SD of four independent experiments in each group. ${ }^{*} p<0.05$ compared to control; ${ }^{\#} p<$ 0.05 compared to rotenone groups (DMRT). manner and approximately half-maximal inhibition of cell viability $(\sim 54.41 \%)$ was obtained at $100 \mathrm{nM}$ rotenone concentration, which corroborated our previous studies [13]. The observed condition mimics the situation at the time of initial diagnosis of $\mathrm{PD}$, when approximately $50 \%$ of neurons in the substantia nigra are alive, although many of them may be undergoing subcellular stress [31]. In the present study, $2 \mathrm{~h}$ prior exposure of vanillin significantly enhanced cell viability in a dose-dependent manner. In this study, the $\mathrm{IC}_{50}$ of vanillin was found at $500 \mu \mathrm{M}$. However, Ho et al. [17] and Lirdprapamongkol et al. [32] showed that the IC $_{50}$ value of vanillin is $400 \mu \mathrm{M}$, on colorectal cancer cell line HT-29 and breast cancer cell line, which indicated its safety. Kim et al. reported that the treatment of vanillin increased undifferentiated neuronal (PC-12) survival against $\mathrm{H}_{2} \mathrm{O}_{2}$ toxicity [33], which is in line with our studies.

Most of the existing reports have suggested that the mitochondrial dysfunction and oxidative stress play a key role in the pathogenesis of neurodegeneration in PD [34]. The mitochondrial respiratory chain (complexes I and III) is one of the most important sites of ROS production, in which complex I could be a critical site of mitochondrial 


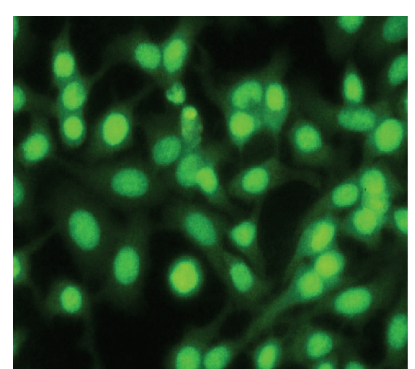

(A)

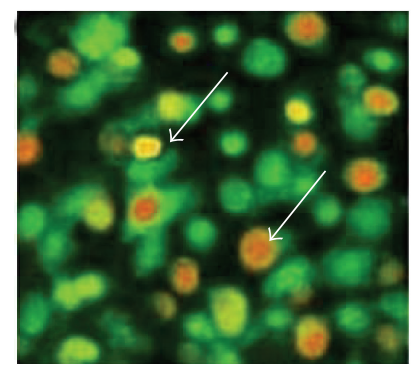

(C)

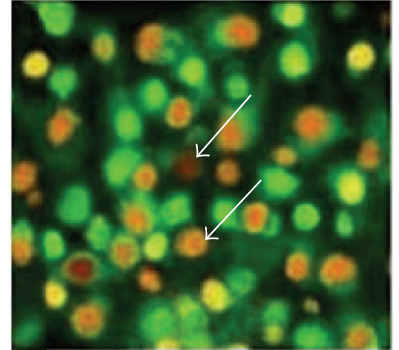

(B)

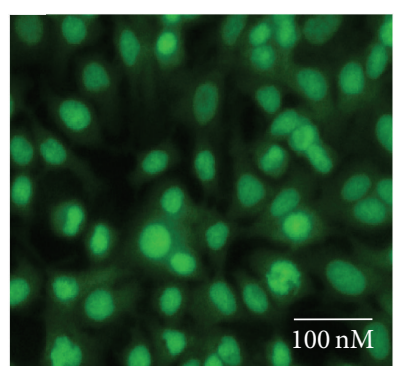

(D)

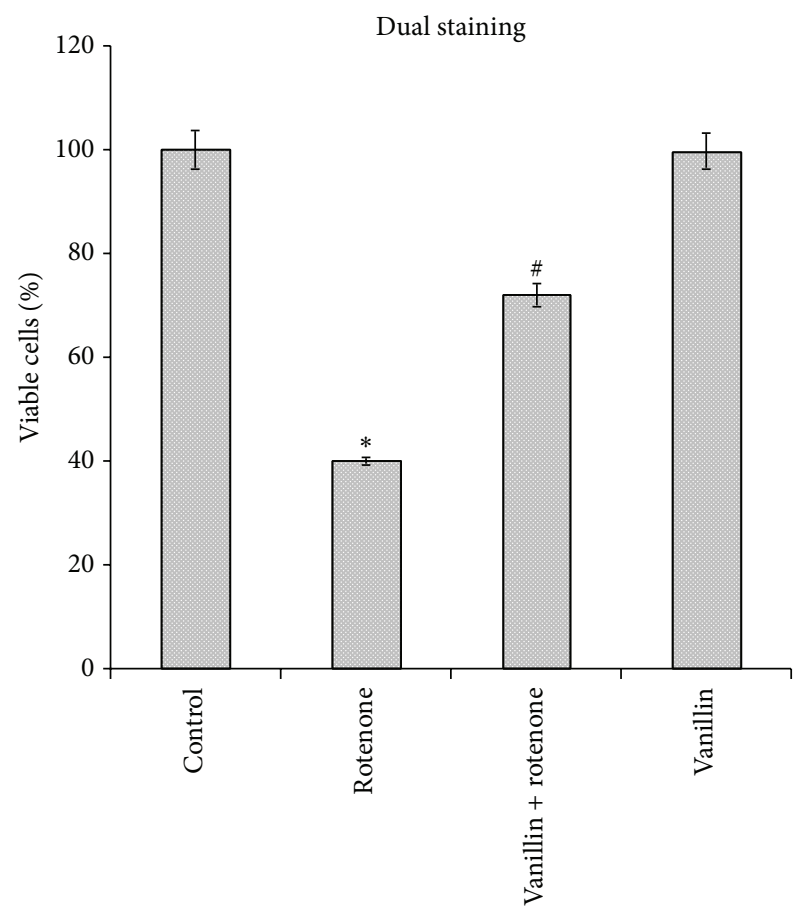

(a)

(b)

FIGURE 6: Vanillin protects SH-SY5Y cells against rotenone induced apoptosis. (a) Photomicrograph showing the antiapoptotic effect of vanillin $(100 \mathrm{nM})$ against rotenone at a concentration of $100 \mathrm{nM}$ effective dose. (A) Control, (B) rotenone, (C) vanillin + rotenone, and (D) vanillin. (b) Rotenone $(100 \mathrm{nM})$ treatment induced cell apoptosis compared to control cells; pretreatment with vanillin (100 nM) suppresses these apoptotic features. Values are given as mean \pm SD of four independent experiments in each group. ${ }^{*} p<0.05$ compared to control and ${ }^{\#} p<0.05$ compared to rotenone group (DMRT).

ROS production and relatively small level of inhibition is sufficient to increase ROS generation [35, 36]. Rotenone is known to bind to complex I of the electron transport chain and prevent the transfer of electrons from iron sulfur clusters to ubiquinone [37], subsequently causing electrons to accumulate within respiratory chain components. These electrons can be added directly to oxygen molecules to produce superoxide $\left(\mathrm{O}_{2}^{-\bullet}\right)$ anion [38]. Formation of $\left(\mathrm{O}_{2}{ }^{-\bullet}\right)$ is also expected to be enhanced significantly via inhibition of $\mathrm{NADH}$ dehydrogenase and enhanced activity of $\mathrm{NAD}(\mathrm{P}) \mathrm{H}$ oxidization [39]. Superoxide dismutase (SOD) catalyzes the dismutation of $\mathrm{O}_{2}{ }^{--}$to $\mathrm{H}_{2} \mathrm{O}_{2}$. Subsequently, $\mathrm{H}_{2} \mathrm{O}_{2}$ is quickly reduced to water by two other enzymes, catalase and glutathione peroxidase (GPx). In the present study, increased levels of ROS observed in the rotenone model indicated that oxidative stress was induced by rotenone and is attenuated by treatment of vanillin which might be because of its free radical scavenging activity. Though vanillin is a potent antioxidant, its alone treatment to SH-SY5Y cells triggers the levels of ROS nonsignificantly. Results of the present study corroborate previous experiments, in which the addition of celastrol, a triterpenoid [40], rutin, a quercetin glycoside [41], and baicalein, a flavonoid [42], alone increased the levels of ROS. Treatment with vanillin ameliorated 3-nitropropionic acid induced impaired mitochondrial enzyme complexes (I,
II, and IV) in experimental model of Huntington's disease [19]. Further it could inhibit singlet oxygen-induced protein and lipid oxidation $[43,44]$. These studies support our current observations.

Rotenone is reported to induce dopaminergic neuronal apoptosis through activation of mitogen-activated protein kinase (MAPK) pathway and caspase-dependent pathway $[45,46]$. Intact MMP is necessary to maintain closure of the multiprotein pore and the mitochondrial permeability transition pore [30,47]. Loss of MMP could lead to opening of the mitochondrial permeability transition pore, through which the cytochrome $c$ is released into the cytosol. Subsequently it forms apoptosome complexes with Apaf-1, dATP, caspase3 , and caspase-9 [48]. Cyt-c release also activates proenzyme caspase-9 (initiator) which subsequently leads to activation of apoptosis executioner caspase-3. The active caspase-3 promotes apoptosis by endonucleases activation resulting in cleavage of cellular substrates and ultimately neuronal death as seen in PD [29].

In the apoptotic cells, Bax, as a proapoptotic protein, interacts with Bid and resulting conformational changes cause the translocation of Bax to the outer mitochondrial membrane where they oligomerize and form protein-permeable channels. This further promotes cell death by releasing cytochrome $\mathrm{c}$ and other lethal factors from the mitochondria 


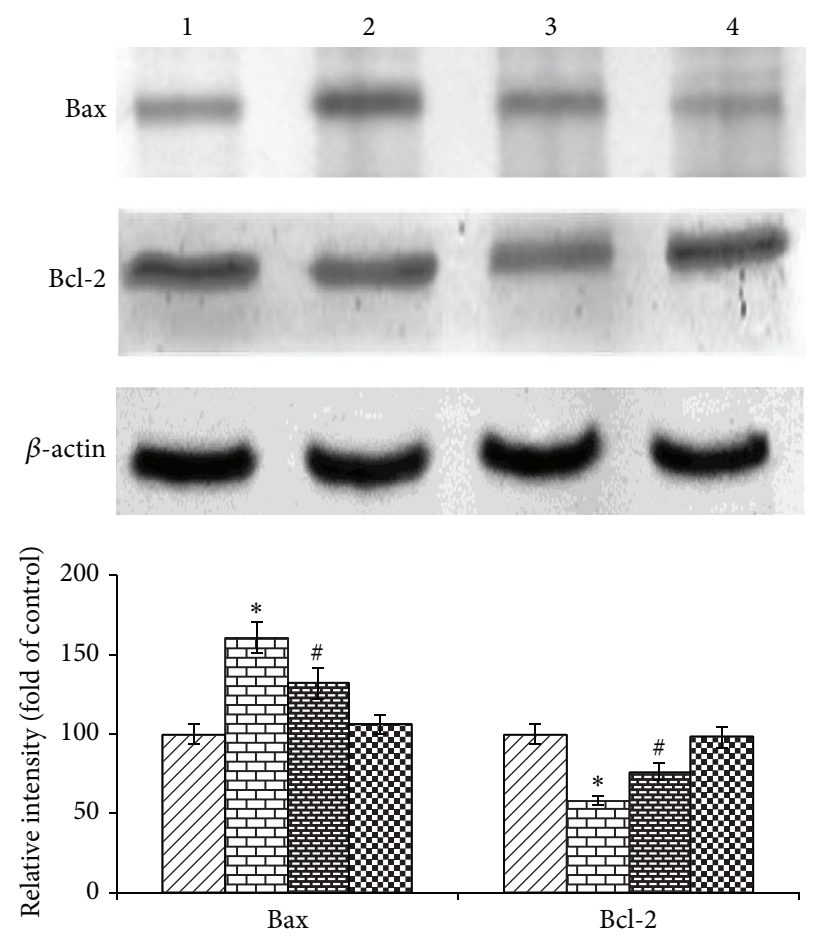

(a)

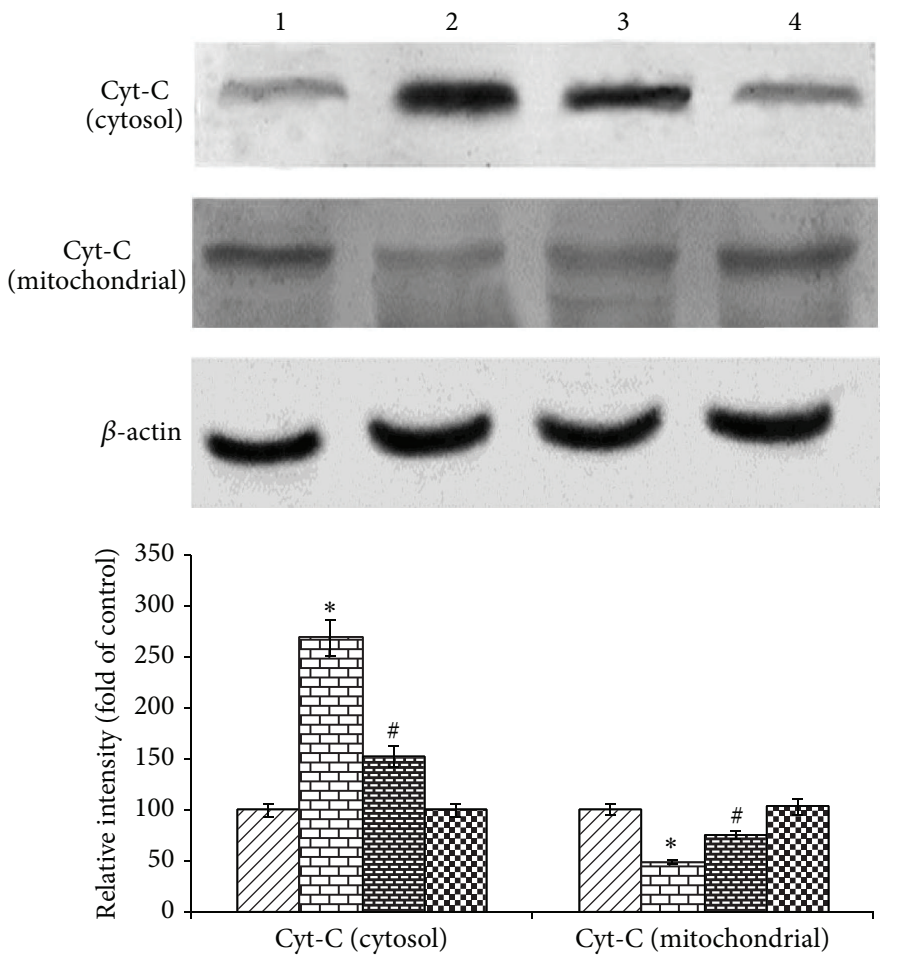

(c)

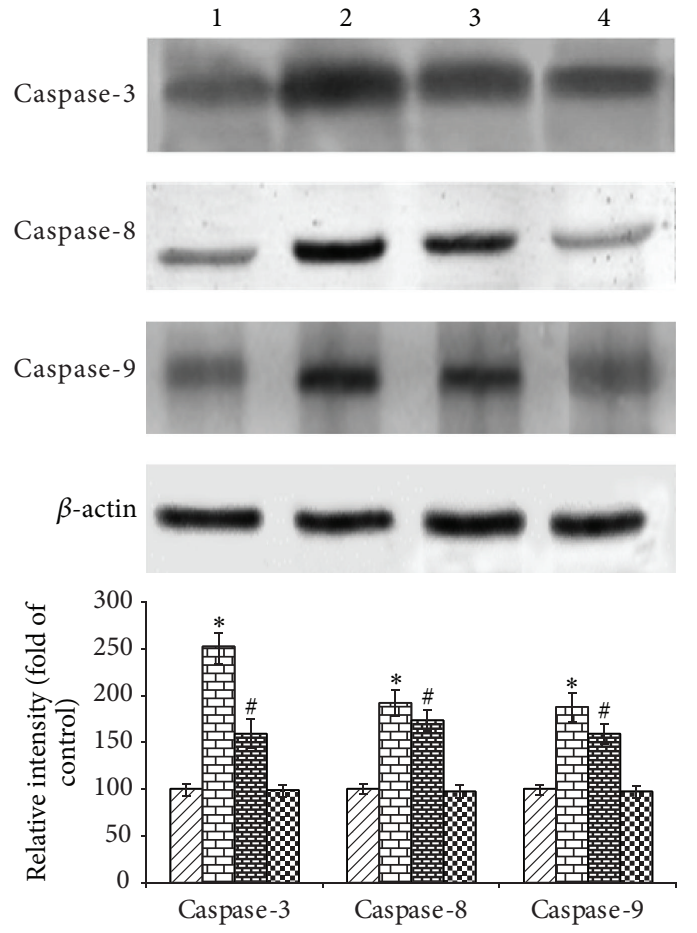

(b)
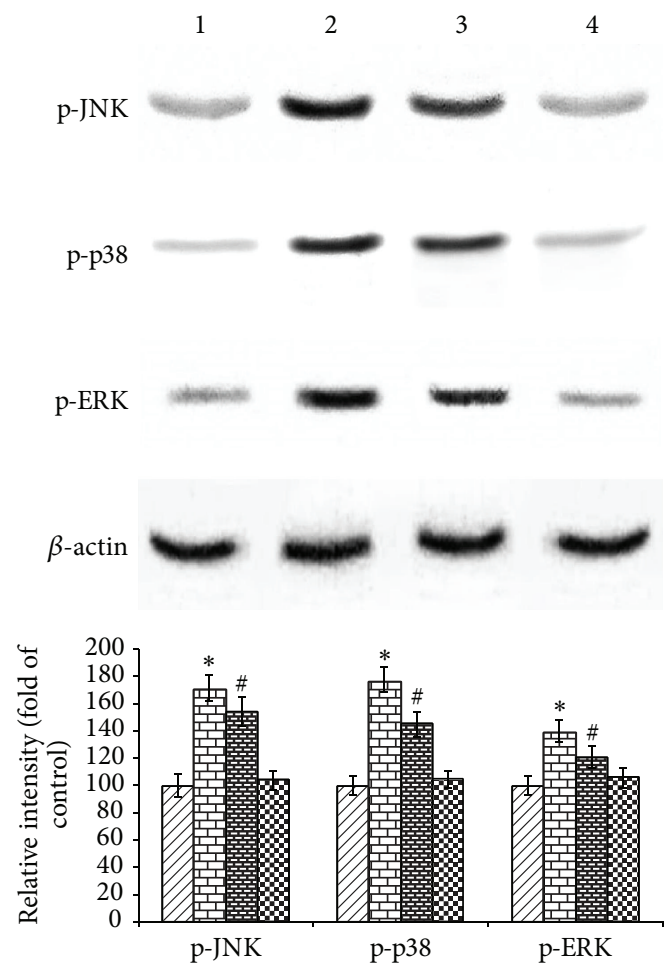

(d)

FIGURE 7: The effect of vanillin on the expressions of apoptotic and signaling markers. Lane 1: control; 2: rotenone; 3: vanillin + rotenone; and 4: vanillin. (a), (b), and (c) show the expressions of Bax; caspase-3, caspase-8, and caspase- 9 cyt-c in cytosol were increased while the expressions of $\mathrm{Bcl}-2$ and cyt-c in mitochondria were significantly decreased by the rotenone treated group as compared with control. Pretreatment with vanillin gradually restored the imbalanced expression profile of these proteins. (d) Rotenone treatment stimulates the expressions of p-JNK, p-P38, and p-ERK as compared with control. Pretreatment with vanillin decreases the expressions of p-JNK, p-P38, and p-ERK significantly. Immunoblots are representative of at least four independent experiments. Values are given as mean \pm SD in each group. ${ }^{*} p<0.05$ compared to control and ${ }^{\#} p<0.05$ compared to rotenone group (DMRT). 
$[49,50] . \mathrm{Bcl}-2$ is an antiapoptotic protein that prevents the loss of MMP, a key event in apoptosis thereby inhibiting the release of cytochrome $\mathrm{c}$ and activation of caspases. Caspases (cysteinyl aspartate-specific proteases) are synthesized as enzymatically inactive precursor proteins (procaspase) and after their activation by proteolytic process leading to apoptosis. Moreover, pro-caspase-2, pro-caspase-3, pro-caspase-8, and pro-caspase- 9 have been found to be abundant in the mitochondrial intermembrane space depending on the cell type. We observed the expressions of caspase-3, caspase-8, and caspase-9 in the untreated SH-SY5Y neuroblastoma cells, which corroborated previous reports $[40,51]$. The characteristic features of apoptosis in rotenone treated SH-SY5Y cells observed in our study are the loss of MMP, enhanced release of cytochrome c, upregulated expressions of caspase-9, caspase-3, and Bax, and diminished expression of Bcl-2. Vanillin pretreatment reversed those apoptotic markers status in our study and showed the possible antiapoptotic properties of vanillin, which may be due to its mitochondrial protective action.

MAPK subfamilies including extracellular-signal regulated kinase 1/2 (ERK1/2), c-Jun NH2-terminal kinase (JNK), and P38 MAPK play diverse roles in the neuronal differentiation, survival, and death $[46,52]$. In the present study, treatment with rotenone induces apoptosis by stimulating the phosphorylation of intracellular 38/JNK MAPK proteins. The activation of 38/JNK MAPK proteins, in turn, induces the apoptosis by recruitment of cytoplasmic Bax to mitochondria and forms permeability transition pore, causing the release of cytochrome c (a death messenger in the cytosol), which further stimulates apoptosis $[46,48,52,53]$. After the entry of Bax into mitochondria, it gets phosphorylated by JNK- and/ or p38K-signaling molecules; the relative contents of Bax in mitochondria may be a key marker for mitochondrial membrane permeability (MMP) change and apoptosis [54]. Cheng et al. reported that the gene ontology and network analysis revealed that genes associated with cancer progression were downregulated by vanillin and suggested that vanillin could be able to influence the regulation of cell cycle and apoptosis signaling molecule in human hepatocarcinoma cells [55].

As a potent insecticide, rotenone primarily inhibits cellular respiratory metabolism in insect tissues, by acting on the nerve cells and then on muscles [56]. Rotenone inhibits the respiration of NADH-linked substrata (excepting succinate) on isolated mitochondria and is not primarily concerned with oxidative phosphorylation [57]. Fukami and Tomizawa [58] concluded that the noted inhibition of in vitro oxidation of L-glutamate in the mitochondrial fraction of insect muscle by rotenone was due to inhibition of glutamic dehydrogenase. In this study, though the impact of vanillin on rotenone depleted activity of GDH is not studied, Lee et al. reported that the vanillin treatment inhibited both intracellular $\mathrm{Ca}^{2+}$ rise and apoptosis induced by glutamate [59]. There were many studies published to show the benefit of natural products and their active components on various neurodegenerative diseases including PD, which further supports the current results [60-66].

Although PD was long considered a nongenetic disorder of "sporadic" origin, 5-10\% of patients are now known to have monogenic forms of the disease. At least 13 loci and 9 genes are associated with both autosomal dominant (PARK1 and PARK4/ $\alpha$-Synuclein; PARK5/UCHL1; PARK8/LRRK2; PARK11/GIGYF2; PARK13/Omi/Htra2) and autosomal recessive (PARK2/Parkin; PARK6/PINK1; PARK7/DJ-1; PARK9/ ATP13A2) PD [67]. To develop the cause-directed therapies, further investigations of the effect of vanillin on expression of these genes are required.

\section{Conclusion}

Beyond its wide usage and commercial values, our findings suggested that vanillin could counteract apoptosis induced by rotenone by preserving mitochondrial functions and antioxidant action. Though rotenone induced in vitro model of PD is considered as a good model, which resembles various pathological features of clinical studies, further extensive research is warranted to find out the effect of vanillin in animal and clinical models of PD.

\section{Conflict of Interests}

Herewith all the authors declare that they do not have any conflict of interests.

\section{Acknowledgment}

Financial assistance in the form of Senior Research Fellowship to C. Dhanalakshmi from the Indian Council of Medical Research (ICMR, New Delhi, India) is gratefully acknowledged.

\section{References}

[1] W. Dauer and S. Przedborski, "Parkinson's disease: mechanisms and models," Neuron, vol. 39, no. 6, pp. 889-909, 2003.

[2] R. Betarbet, T. B. Sherer, G. MacKenzie, M. Garcia-Osuna, A. V. Panov, and J. T. Greenamyre, "Chronic systemic pesticide exposure reproduces features of Parkinson's disease," Nature Neuroscience, vol. 3, no. 12, pp. 1301-1306, 2000.

[3] M. Alam and W. J. Schmidt, "Rotenone destroys dopaminergic neurons and induces parkinsonian symptoms in rats," Behavioural Brain Research, vol. 136, no. 1, pp. 317-324, 2002.

[4] J. T. Greenamyre, R. Betarbet, and T. B. Sherer, “The rotenone model of Parkinson's disease: genes, environment and mitochondria," Parkinsonism and Related Disorders, vol. 9, supplement 2, pp. S59-S64, 2003.

[5] T. B. Sherer, J. R. Richardson, C. M. Testa et al., "Mechanism of toxicity of pesticides acting at complex I: relevance to environmental etiologies of Parkinson's disease," Journal of Neurochemistry, vol. 100, no. 6, pp. 1469-1479, 2007.

[6] H.-R. Xie, L.-S. Hu, and G.-Y. Li, "SH-SY5Y human neuroblastoma cell line: in vitro cell model of dopaminergic neurons in Parkinson's disease," Chinese Medical Journal, vol. 123, no. 8, pp. 1086-1092, 2010.

[7] J. M. Gorell, C. C. Johnson, B. A. Rybicki, E. L. Peterson, and R. J. Richardson, "The risk of Parkinson's disease with exposure to pesticides, farming, well water, and rural living," Neurology, vol. 50, no. 5, pp. 1346-1350, 1998. 
[8] A. Menegon, P. G. Board, A. C. Blackburn, G. D. Mellick, and D. G. Le Couteur, "Parkinson's disease, pesticides, and glutathione transferase polymorphisms," The Lancet, vol. 352, no. 9137, pp. 1344-1346, 1998.

[9] J. B. Martins, M. D. L. Bastos, F. Carvalho, and J. P. Capela, "Differential effects of methyl-4-phenylpyridinium ion, rotenone, and Paraquat on differentiated SH-SY5Y cells," Journal of Toxicology, vol. 2013, Article ID 347312, 10 pages, 2013.

[10] M. E. Obrenovich, N. G. Nair, A. Beyaz, G. Aliev, and V. P. Reddy, "The role of polyphenolic antioxidants in health, disease, and aging," Rejuvenation Research, vol. 13, no. 6, pp. 631-643, 2010.

[11] B. L. Queen and T. O. Tollefsbol, "Polyphenols and aging," Current Aging Science, vol. 3, no. 1, pp. 34-42, 2010.

[12] M. M. Essa, R. K. Vijayan, G. Castellano-Gonzalez, M. A. Memon, N. Braidy, and G. J. Guillemin, "Neuroprotective effect of natural products against Alzheimer's disease," Neurochemical Research, vol. 37, no. 9, pp. 1829-1842, 2012.

[13] M. Kavitha, T. Manivasagam, M. M. Essa et al., "Mangiferin antagonizes rotenone: induced apoptosis through attenuating mitochondrial dysfunction and oxidative stress in SK-N-SH neuroblastoma cells," Neurochemical Research, vol. 39, no. 4, pp. 668-676, 2014.

[14] S. R. Rao and G. A. Ravishankar, "Vanilla flavour: production by conventional and biotechnological routes," Journal of the Science of Food and Agriculture, vol. 80, no. 3, pp. 289-304, 2000.

[15] S. Rakchoy, P. Suppakul, and T. Jinkarn, "Antimicrobial effects of vanillin coated solution for coating paper board intended for packaging bakery products," Asian Journal of Food \& Agroindustry, vol. 2, no. 4, pp. 138-147, 2009.

[16] H. Imanishi, Y. Sasaki, K. Matsumoto et al., "Suppression of 6TG-resistant mutations in V79 cells and recessive spot formations in mice by vanillin," Mutation Research Letters, vol. 243, no. 2, pp. 151-158, 1990.

[17] K. Ho, L. S. Yazan, N. Ismail, and M. Ismail, "Apoptosis and cell cycle arrest of human colorectal cancer cell line HT-29 induced by vanillin," Cancer Epidemiology, vol. 33, no. 2, pp. 155-160, 2009.

[18] S. S. Kumar, K. I. Priyadarsini, and K. B. Sainis, "Inhibition of peroxynitrite-mediated reactions by vanillin," Journal of Agricultural and Food Chemistry, vol. 52, no. 1, pp. 139-145, 2004.

[19] S. Gupta and B. Sharma, "Pharmacological benefits of agomelatine and vanillin in experimental model of Huntington's disease," Pharmacology Biochemistry and Behavior, vol. 122, pp. 122-135, 2014.

[20] S.-L. Wu, J.-C. Chen, C.-C. Li, H.-Y. Lo, T.-Y. Ho, and C.Y. Hsiang, "Vanillin improves and prevents trinitrobenzene sulfonic acid-induced colitis in mice," Journal of Pharmacology and Experimental Therapeutics, vol. 330, no. 2, pp. 370-376, 2009.

[21] M. Makni, Y. Chtourou, E. M. Garoui, T. Boudawara, and H. Fetoui, "Carbon tetrachloride-induced nephrotoxicity and DNA damage in rats: protective role of vanillin," Human and Experimental Toxicology, vol. 31, no. 8, pp. 844-852, 2012.

[22] J. T. Greenamyre, J. R. Cannon, R. Drolet, and P.-G. Mastroberardino, "Lessons from the rotenone model of Parkinson's disease," Trends in Pharmacological Sciences, vol. 31, no. 4, pp. 141-142, 2010.
[23] B. V. Manyam and J. R. Sánchez-Ramos, "Traditional and complementary therapies in Parkinson's disease," Advances in Neurology, vol. 80, pp. 565-574, 1999.

[24] Q. Li, D. Zhao, and E. Bezard, "Traditional Chinese medicine for Parkinson's disease: a review of Chinese literature," Behavioural Pharmacology, vol. 17, no. 5-6, pp. 403-410, 2006.

[25] T. Mosmann, "Rapid colorimetric assay for cellular growth and survival: application to proliferation and cytotoxicity assays," Journal of Immunological Methods, vol. 65, no. 1-2, pp. 55-63, 1983.

[26] K. Hafer, K. S. Iwamoto, and R. H. Schiestl, "Refinement of the dichlorofluorescein assay for flow cytometric measurement of reactive oxygen species in irradiated and bystander cell populations," Radiation Research, vol. 169, no. 4, pp. 460-468, 2008.

[27] B. Halliwell and M. Whiteman, "Measuring reactive species and oxidative damage in vivo and in cell culture: how should you do it and what do the results mean?" British Journal of Pharmacology, vol. 142, no. 2, pp. 231-255, 2004.

[28] L. V. Johnson, M. L. Walsh, and L. B. Chen, "Localization of mitochondria in living cells with rhodamine 123," Proceedings of the National Academy of Sciences of the United States of America, vol. 77, no. 2, pp. 990-994, 1980.

[29] R. L. Jayaraj, K. Tamilselvam, T. Manivasagam, and N. Elangovan, "Neuroprotective effect of CNB-001, a novel pyrazole derivative of curcumin on biochemical and apoptotic markers against rotenone-induced SK-N-SH cellular model of parkinson's disease," Journal of Molecular Neuroscience, vol. 51, no. 3, pp. 863-870, 2013.

[30] L.-F. Hu, M. Lu, Z.-Y. Wu, P. T.-H. Wong, and J.-S. Bian, "Hydrogen sulfide inhibits rotenone-induced apoptosis via preservation of mitochondrial function," Molecular Pharmacology, vol. 75, no. 1, pp. 27-34, 2009.

[31] H. Bernheimer, W. Birkmayer, O. Hornykiewicz, K. Jellinger, and F. Seitelberger, "Brain dopamine and the syndromes of Parkinson and Huntington. Clinical, morphological and neurochemical correlations," Journal of the Neurological Sciences, vol. 20, no. 4, pp. 415-455, 1973.

[32] K. Lirdprapamongkol, H. Sakurai, N. Kawasaki et al., "Vanillin suppresses in vitro invasion and in vivo metastasis of mouse breast cancer cells," European Journal of Pharmaceutical Sciences, vol. 25, no. 1, pp. 57-65, 2005.

[33] H. J. Kim, I. K. Hwang, and M. H. Won, "Vanillin, 4-hydroxybenzyl aldehyde and 4-hydroxybenzyl alcohol prevent hippocampal CA1 cell death following global ischemia," Brain Research, vol. 1181, no. 1, pp. 130-141, 2007.

[34] A. Bender, K. J. Krishnan, C. M. Morris et al., "High levels of mitochondrial DNA deletions in substantia nigra neurons in aging and Parkinson disease," Nature Genetics, vol. 38, no. 5, pp. 515-517, 2006.

[35] T. A. Seaton, J. M. Cooper, and A. H. V. Schapira, "Free radical scavengers protect dopaminergic cell lines from apoptosis induced by complex I inhibitors," Brain Research, vol. 777, no. 1-2, pp. 110-118, 1997.

[36] D. J. Talpade, J. G. Greene, D. S. Higgins, and J. T. Greenamyre, "In vivo labeling of mitochondrial complex I (NADH: ubiquinone oxidoreductase) in rat brain using $\left[{ }^{3} \mathrm{H}\right]$ dihydrorotenone," Journal of Neurochemistry, vol. 75, no. 6, pp. 2611$2621,2000$. 
[37] W. J. H. Koopman, L. G. J. Nijtmans, C. E. J. Dieteren et al., "Mammalian mitochondrial complex I: biogenesis, regulation, and reactive oxygen species generation," Antioxidants and Redox Signaling, vol. 12, no. 12, pp. 1431-1470, 2010.

[38] J. F. Turrens, "Mitochondrial formation of reactive oxygen species," The Journal of Physiology, vol. 552, no. 2, pp. 335-344, 2003.

[39] J. F. Turrens, "Superoxide production by the mitochondrial respiratory chain," Bioscience Reports, vol. 17, no. 1, pp. 3-8, 1997.

[40] B.-S. Choi, H. Kim, H. J. Lee et al., "Celastrol from 'Thunder God Vine' protects SH-SY5Y cells through the preservation of mitochondrial function and inhibition of p38 mapk in a rotenone model of parkinson's disease," Neurochemical Research, vol. 39, no. 1, pp. 84-96, 2014.

[41] S.-E. Park, K. Sapkota, J.-H. Choi et al., "Rutin from dendropanax morbifera leveille protects human dopaminergic cells against rotenone induced cell injury through inhibiting JNK and p38 MAPK signaling," Neurochemical Research, vol. 39, no. 4, pp. 707-718, 2014.

[42] J.-X. Song, M. Y.-M. Choi, K. C.-K. Wong et al., "Baicalein antagonizes rotenone-induced apoptosis in dopaminergic $\mathrm{SH}$ SY5Y cells related to Parkinsonism," Chinese Medicine, vol. 7, article 1, 2012.

[43] J. P. Kamat, A. Ghosh, and T. P. A. Devasagayam, "Vanillin as an antioxidant in rat liver mitochondria: inhibition of protein oxidation and lipid peroxidation induced by photosensitization," Molecular and Cellular Biochemistry, vol. 209, no. 1-2, pp. 47-53, 2000.

[44] S. Santosh Kumar, K. I. Priyadarsini, and K. B. Sainis, "Free radical scavenging activity of vanillin and o-vanillin using 1,1diphenyl-2-picrylhydrazyl (DPPH) radical," Redox Report, vol. 7, no. 1, pp. 35-40, 2002.

[45] H. Klintworth, K. Newhouse, T. Li, W.-S. Choi, R. Faigle, and Z. Xia, "Activation of c-Jun N-terminal protein kinase is a common mechanism underlying paraquat- and rotenone-induced dopaminergic cell apoptosis," Toxicological Sciences, vol. 97, no. 1, pp. 149-162, 2007.

[46] E. Junn and M. M. Mouradian, "Apoptotic signaling in dopamine-induced cell death: the role of oxidative stress, p38 mitogenactivated protein kinase, cytochrome $c$ and caspases," Journal of Neurochemistry, vol. 78, no. 2, pp. 374-383, 2001.

[47] W. G. Tatton and C. W. Olanow, "Apoptosis in neurodegenerative diseases: the role of mitochondria," Biochimica et Biophysica Acta: Bioenergetics, vol. 1410, no. 2, pp. 195-213, 1999.

[48] P. Li, D. Nijhawan, I. Budihardjo et al., "Cytochrome c and dATP-dependent formation of Apaf-1/caspase- 9 complex initiates an apoptotic protease cascade," Cell, vol. 91, no. 4, pp. 479489, 1997.

[49] V. Gogvadze, S. Orrenius, and B. Zhivotovsky, "Multiple pathways of cytochrome $c$ release from mitochondria in apoptosis," Biochimica et Biophysica Acta-Bioenergetics, vol. 1757, no. 5-6, pp. 639-647, 2006.

[50] J. C. Reed, "Proapoptotic multidomain Bcl-2/Bax-family proteins: mechanisms, physiological roles, and therapeutic opportunities," Cell Death \& Differentiation, vol. 13, no. 8, pp. 13781386, 2006.

[51] C. X. Wang, J. H. Song, D. K. Song, V. W. Yong, A. Shuaib, and C. Hao, "Cyclin-dependent kinase-5 prevents neuronal apoptosis through ERK-mediated upregulation of Bcl-2," Cell Death and Differentiation, vol. 13, no. 7, pp. 1203-1212, 2006.
[52] R. J. Davis, "Signal transduction by the JNK group of MAP kinases," Cell, vol. 103, no. 2, pp. 239-252, 2000.

[53] Z. Xia, M. Dickens, J. Raingeaud, R. J. Davis, and M. E. Greenberg, "Opposing effects of ERK and JNK-p38 MAP kinases on apoptosis," Science, vol. 270, no. 5240, pp. 1326-1331, 1995.

[54] B.-J. Kim, S.-W. Ryu, and B.-J. Song, "JNK- and p38 kinasemediated phosphorylation of Bax leads to its activation and mitochondrial translocation and to apoptosis of human hepatoma HepG2 cells," The Journal of Biological Chemistry, vol. 281, no. 30, pp. 21256-21265, 2006.

[55] W.-Y. Cheng, C.-Y. Hsiang, D.-T. Bau et al., "Microarray analysis of vanillin-regulated gene expression profile in human hepatocarcinoma cells," Pharmacological Research, vol. 56, no. 6, pp. 474-482, 2007.

[56] L. Ernster, G. Dallner, and G. F. Azzone, "Differential effect of rotenone and amytal on mitochondrial electron and energy transfer," The Journal of Biological Chemistry, vol. 238, no. 3, pp. 1124-1131, 1963.

[57] J. Fukami, T. Nakatsugawa, and T. Narahashi, "The relation between chemical structure and toxicity in rotenone derivatives," Japanese Journal of Applied Entomology and Zoology, vol. 3, no. 4, pp. 256-265, 1959.

[58] J. Fukami and C. Tomizawa, "Effect of rotenone on the l-glutamic oxidase system in insect," Botyu-Kagaku, vol. 21, pp. 129$113,1956$.

[59] Y. S. Lee, J.-H. Ha, C. S. Yong et al., "Inhibitory effects of constituents of Gastrodia elata Bl. on glutamate-induced apoptosis in IMR-32 human neuroblastoma cells," Archives of Pharmacal Research, vol. 22, no. 4, pp. 404-409, 1999.

[60] K. Tamilselvam, J. Nataraj, U. Janakiraman, T. Manivasagam, and M. M. Essa, "Antioxidant and anti-inflammatory potential of hesperidin against 1-methyl-4-phenyl-1, 2, 3, 6-tetrahydropyridine-induced experimental Parkinson's disease in mice," International Journal of Nutrition, Pharmacology, Neurological Diseases, vol. 3, no. 3, pp. 294-302, 2013.

[61] M. M. Essa, S. Subash, C. Dhanalakshmi et al., "Dietary supplementation of walnut partially reverses 1-methyl-4-phenyl1,2,3,6-tetrahydropyridine induced neurodegeneration in a mouse model of Parkinson's disease," Neurochemical Research, vol. 40, no. 6, pp. 1283-1293, 2015.

[62] N. Braidy, S. Selvaraju, M. M. Essa et al., "Neuroprotective effects of a variety of pomegranate juice extracts against MPTPinduced cytotoxicity and oxidative stress in human primary neurons," Oxidative Medicine and Cellular Longevity, vol. 2013, Article ID 685909, 12 pages, 2013.

[63] V. Singh, N. Guizani, M. M. Essa, F. L. Hakkim, and M. S. Rahman, "Comparative analysis of total phenolics, flavonoid content and antioxidant profile of different date varieties (Phoenix dactylifera L.) from sultanate of Oman," International Food Research Journal, vol. 19, no. 3, pp. 1063-1070, 2012.

[64] K. Tamilselvam, N. Braidy, T. Manivasagam et al., "Neuroprotective effects of hesperidin, a plant flavanone, on rotenoneinduced oxidative stress and apoptosis in a cellular model for Parkinson's disease," Oxidative Medicine and Cellular Longevity, vol. 2013, Article ID 102741, 11 pages, 2013.

[65] M. Kavitha, J. Nataraj, M. M. Essa, M. A. Memon, and T. Manivasagam, "Mangiferin attenuates MPTP induced dopaminergic neurodegeneration and improves motor impairment, redox balance and Bcl-2/Bax expression in experimental Parkinson's disease mice," Chemico-Biological Interactions, vol. 206, no. 2, pp. 239-247, 2013. 
[66] A. Anandhan, M. M. Essa, and T. Manivasagam, "Therapeutic attenuation of neuroinflammation and apoptosis by black tea theaflavin in chronic MPTP/Probenecid model of parkinson's disease," Neurotoxicity Research, vol. 23, no. 2, pp. 166-173, 2013.

[67] S. Lesage and A. Brice, "Parkinson's disease: from monogenic forms to genetic susceptibility factors," Human Molecular Genetics, vol. 18, no. 1, pp. R48-R59, 2009. 


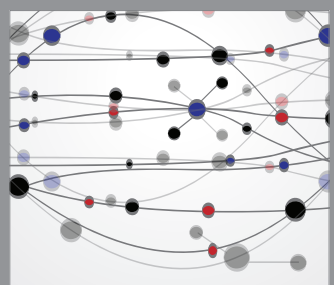

The Scientific World Journal
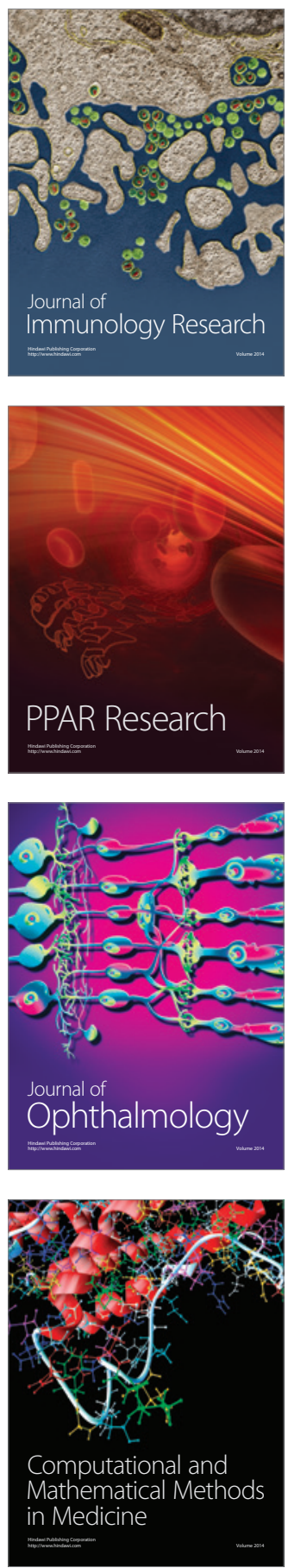

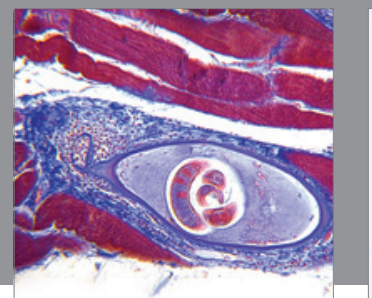

Gastroenterology

Research and Practice
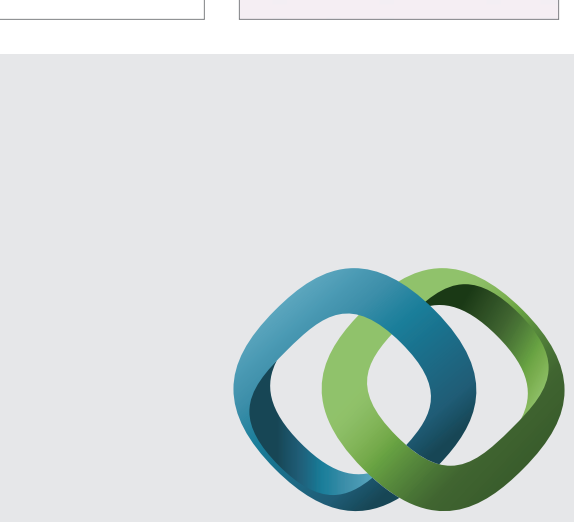

\section{Hindawi}

Submit your manuscripts at

http://www.hindawi.com
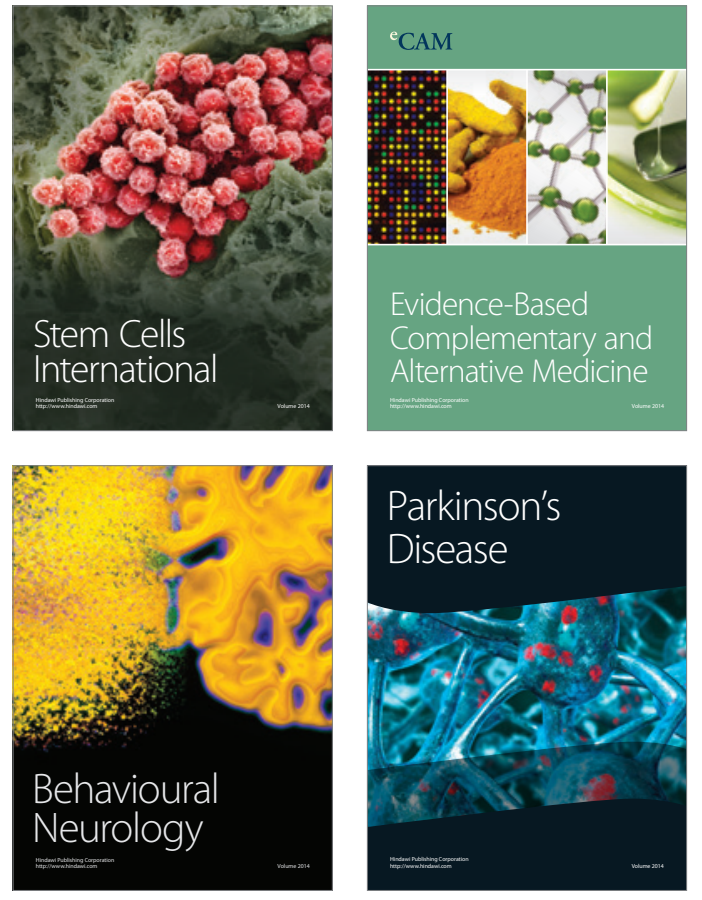
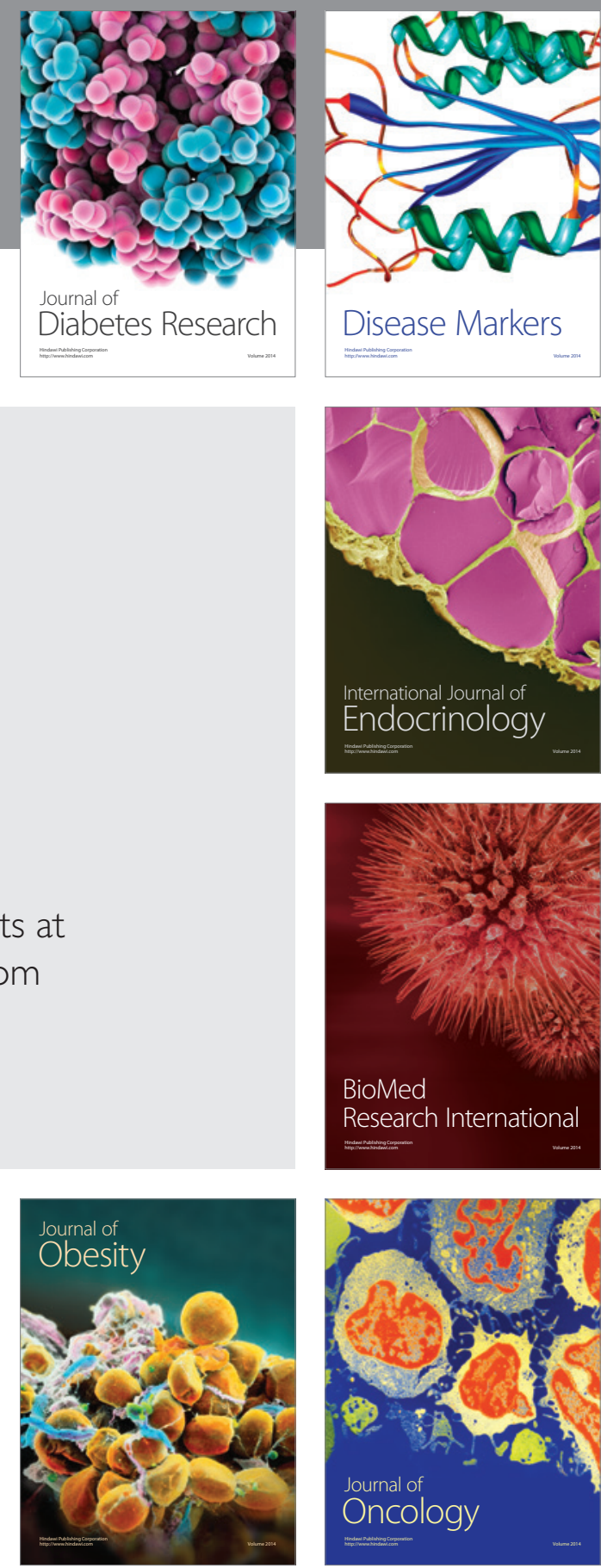

Disease Markers
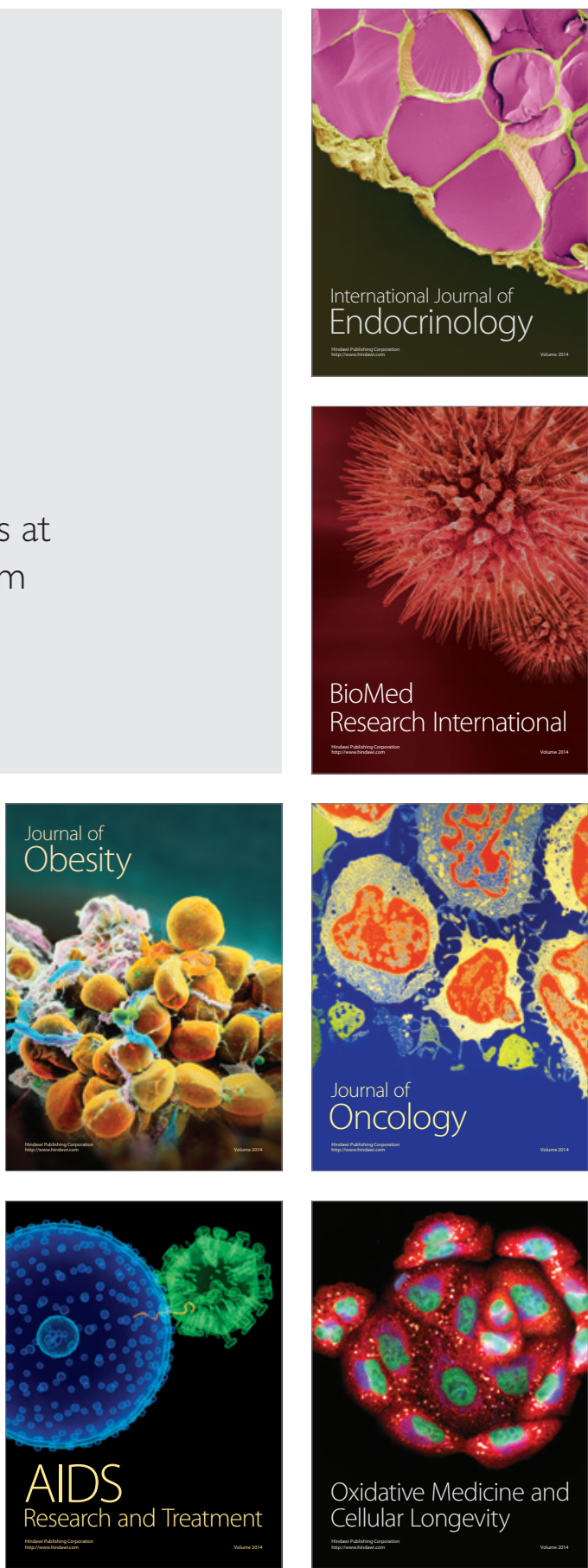